\title{
Article \\ Challenges of High Renewable Energy Sources Integration in
Power Systems-The Case of Croatia
}

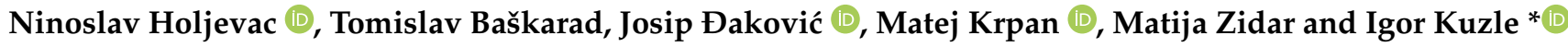

Department of Energy and Power Systems, Faculty of Electrical Engineering and Computing, University of Zagreb, Unska 3, 10000 Zagreb, Croatia; ninoslav.holjevac@fer.hr (N.H.); tomislav.baskarad@fer.hr (T.B.); josip.djakovic@fer.hr (J.Đ.); matej.krpan@fer.hr (M.K.); matija.zidar@fer.hr (M.Z.)

* Correspondence: igor.kuzle@fer.hr

Citation: Holjevac, N.; Baškarad, T.; Đaković, J.; Krpan, M.; Zidar, M.; Kuzle, I. Challenges of High Renewable Energy Sources Integration in Power Systems-The Case of Croatia. Energies 2021, 14, 1047. https://doi.org/10.3390/ en14041047

Academic Editor: Edris Pouresmaeil

Received: 31 December 2020

Accepted: 8 February 2021

Published: 17 February 2021

Publisher's Note: MDPI stays neutral with regard to jurisdictional claims in published maps and institutional affiliations.

Copyright: (c) 2021 by the authors. Licensee MDPI, Basel, Switzerland. This article is an open access article distributed under the terms and conditions of the Creative Commons Attribution (CC BY) license (https:/ / creativecommons.org/licenses/by/ $4.0 /)$.

\begin{abstract}
This paper presents a high-level overview of the integration of renewable energy sources (RES), primarily wind and solar, into the electric power system (EPS) in Croatia. It presents transmission system integration aspects for the particular case of this country. It explains the current situation and technical characteristics of the current conventional generation units and currently installed wind energy capacities. Based on the current situation future development scenario is determined and used to evaluate the impacts of the wide-scale integration of renewables. Grid connections aspects, power balancing, market participation, and inertia reduction aspects are considered. Furthermore, some specifics of both solar and wind integration are discussed identifying problems and potential solutions. Primarily through the provision of the inertial response of both solar and wind and through better forecasting of wind production. Finally, the outlook for the Croatian power system is given, that will most probably double its RES capacity in the coming 3-year period and a certain level of investments and changes of current operational practices will need to be provided.
\end{abstract}

Keywords: renewable energy sources; power system inertia; transmission system

\section{Introduction \\ 1.1. Motivation and Background}

Wind and solar energy are the fastest growing renewable energy sources (RES) in the world: according to the International Renewable Energy Agency [1], at the end of 2019, installed wind and solar energy in the world increased to $623 \mathrm{GW}$ and $586 \mathrm{GW}$ respectively. Compared to the previous year, this is an increase of around $10 \%$ for wind power plants and $20 \%$ for solar power plants. The Croatian electric power system, like other power systems, is also experiencing a trend of a massive penetration of renewable energy sources. Although the current wind and solar capacities are relatively high (almost $900 \mathrm{MW}$ ) compared to the peak load of $3100 \mathrm{MW}$, the actual energy production is still rather low (up to $12 \%$ of the total energy of $17 \mathrm{TWh}$ ) due to the intermittency of these sources. Nevertheless, wind and solar production may reach high instantaneous levels in a short time frame (e.g., day or month) even though the average capacity factor in a year is around $30 \%$ for these technologies [2]. A recent example of this for Croatian EPS was in September 2020 when wind farms were covering around $50 \%$ of the hourly system demand, while on average this share was around $15 \%$ on daily basis [3].

Recently, in the power systems on a wider scale, solid-state power converters such as DC/DC choppers, DC/AC inverters, AC/ AC cyclo-converters, and AC/DC rectifiers are extensively used in the generation, load, transmission, and distribution subsystems to provide power at different voltage levels at both DC and AC forms. It is a well-known fact that there is an enormous rate of penetration of inverter-connected distributed generation (DG), most notably wind and PV both on distribution and transmission levels. Any power plant which is currently in operation, or will be soon, can be connected through an inverter interface ranging from micro hydropower plants to thermal power plants 
regardless of the type of energy resource. Inverters ensure power generation at nominal power system frequency while generally isolating the energy source from the grid faults. In general, power electronic devices provide flexible and superior control compared to the traditional control of synchronous machines [4]. A contemporary bulk power system such as the European one is very well interconnected between the countries and has a large amount of synchronous generation (traditional synchronous generators in fossil fuel thermal power plants, gas power plants, hydropower plants, and nuclear power plants), but there are already conducted analysis on the inertia requirements for European EPS for 2050 [5]. Interconnection and synchronous generators make the whole system stronger and more resilient [6]. According to the IEEE/CIGRE Joint Task Force on Stability Terms and Definitions, power system stability can be classified into: (1) rotor angle stability; (2) frequency stability; (3) voltage stability [7]. Currently, all of those are ensured mostly by synchronous generators. That is, rotor angle dynamics and frequency dynamics are mostly related to the active power imbalances between the generation and load, and the amount of synchronous inertia (a measure of kinetic energy in the spinning turbine-generators) in the system as well as turbine-governing systems for frequency control. On the other hand, voltage dynamics is mostly related to reactive power imbalances in the system where the power system loads are the major driving force for the voltage instability, especially in systems where synchronous generators are the main sources of reactive power. RES integration could cause voltage instabilities if connected to a weak AC system [8]. Most grid-connected converters are grid-following meaning that they require a stable voltage as a source of frequency and voltage reference (Figure 1). The sources of stable voltage and frequency are the synchronous machines. Removing synchronous machines means that there is no frequency reference in the grid, thereby removing the explicit relationship between grid frequency and rotational speed of the machines which means that there is no natural indicator of the active power imbalance in the grid.

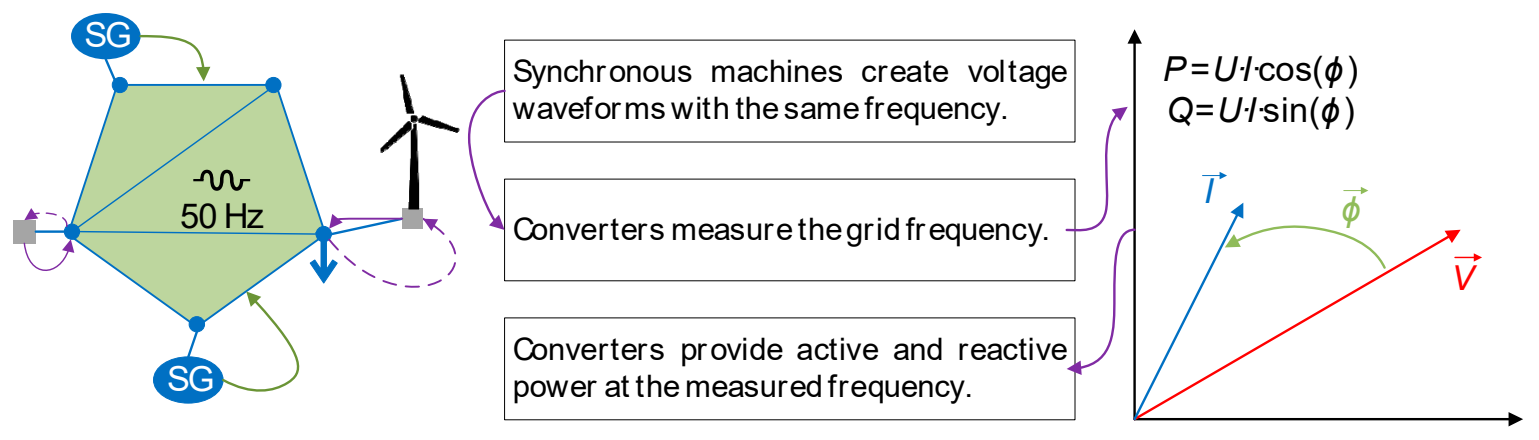

Figure 1. Operational concept of conventional grid-following converters [2].

Decrease of synchronous grid inertia is the consequence of inverter-connected generation that is the most popular topic among the research community in recent years and a lot of papers focused on frequency support services from inverter-based resources, especially wind power plants [9], photovoltaic systems [10], and energy storage [11]. It may seem that the answer to the low-carbon electricity sector is just to gradually replace fossil-fuel power plants with wind and solar. However, it is important to say that the implications of a high share of inverter-based generation are far wider than just frequency control and three key issues must be addressed:

(a) Power system dynamics and stability-it is currently technologically infeasible to operate a large power system with a significant share (e.g., $>50 \%$ ) of wind and solar resources due to how these units are connected to the grid via the power electronics interface. By replacing conventional power plants, this type of interface reduces the strength of the grid to disturbances which in turn jeopardizes the dynamic stability of the system and may lead to cascaded blackouts resulting in enormous economic losses. Frequency dynamics are mostly related to the active power imbalances between the generation and 
load, and the amount of synchronous inertia in the system as well as turbine-governing systems for frequency control [12]. Although dynamic and stability issues still need to be addressed for $100 \%$ RES-based power system, some studies, such as one presented in [13], have already shown the possibility of achieving $100 \%$ RES-based power systems by analyzing the requirements for providing virtual inertia response from WPP and PVS.

(b) Ancillary services-ancillary services are necessary services that ensure stable and reliable transfer of electrical power from suppliers to consumers. These services are normally provided by conventional generation units. Wind and solar generally do not participate in these services, but they will have to be included in these services in the future when their share becomes significant [14]. RES are spatially scattered and could be able to provide local services, either through local markets or through long-term contracts.

(c) Power system planning and RES forecasting-RES are highly dependent on input stochastic energy sources such as solar radiation, wind speed, temperature, etc. When the share of RES is significant, accurate wind and solar power forecasting alongside the stochastic component and uncertainty of wind and solar must be included in the unit commitment problem. This is necessary if wind and solar are to participate in ancillary services. Accurate prediction of RES power output is crucial for both power system operators and for RES itself [15]. In a low-carbon energy system, a transmission system operator must design requirements for frequency ancillary services based on future demand as well as future RES generation.

\subsection{Literature Survey}

An extensive review of the challenges posed by RES integration for the power system is presented in [16]. The challenges are analyzed for both conventional and future power systems. Recently, a lot of papers present an analysis of the RES integration impact on the specific power system: in [17], the analysis of the RES integration challenges in Indonesia with the emphasis on the duck curve phenomenon is presented; the requirements and feasibility of the future RES scenario for 2030 and 2050 in Norway is analyzed in [18]; wind power integration aspects for The Netherlands power system is presented in [19]; the dynamic analysis focused on the system frequency control of the Madeira Island EPS is conducted in [20]; A detailed analysis of small island power systems considering increased RES integration and their impact on system stability is presented in [21]; in addition to small island systems, the paper [22] presents a comprehensive analysis of multi-carrier energy systems consisting of various energy resources and proposes an optimal component combination to minimize power system costs. Wind turbine siting scenario is analyzed for German EPS to achieve a 40\% share of wind power production in total consumption [23]; cost-effectiveness analysis of replacing existing wind turbine generators with new ones within wind power farms for the Spanish EPS is presented in [24]. Another cost analysis, related to wind power plants, is conducted for the Chinese system [25]. The focus was on the variability, intermittency, and exploitability of wind energy in China. Not only onshore wind farms, but also offshore wind farms can be of great importance in achieving goals of required RES production share. An example of this is the UK system whose installed capacity in offshore wind farms is around half of the total world capacity [26]. However, in Croatia, offshore wind power plants are not expected in the near future due to different wind conditions and nature protection aspects.

An interesting aspect of using RES energy, especially in the situation of high renewable energy production, is where excess RES energy, which cannot be transferred by transmission lines due to limited transmission capacity, could be used to produce hydrogen or synthetic natural gas [27]. A case study of Italy power system shows that due to the current transmission limitations between the north and south parts of Italy, excess energy from RES could increase up to $40 \%$ of the total hydrogen production [28]. However, the so-called power to gas solution is not considered in this paper. 


\subsection{Contributions}

This paper presents the challenges Croatian EPS is facing in terms of the abovementioned key issues: current and future scenarios concerning the RES integration, the impacts of increased wind power plants and photovoltaic power plants integration on the system frequency stability, RES requirements to participate in ancillary services and the importance and application of wind power production forecasting.

All the segments are presented as follows: Section 2 describes the specifics of the Croatian EPS, Section 3 shows future RES integration and inertia reduction scenarios, Section 4 shows the specifics of PV integration while Section 5 shows specifics of wind integration with a focus on production forecasting importance. Section 6 summarizes and concludes the paper.

\section{Specifics of Croatian Power System}

The Croatian power system has a distinctive topology which makes the power flow control demanding. As the Croatian power system was conceived during the period when Croatia was part of a larger country (Yugoslavia) which included all of the neighboring countries (e.g., Serbia, Bosnia and Hercegovina, and Slovenia) there is no high voltage mesh. There is one transmission system operator (TSO)—HOPS and one distribution system operator (DSO)_HEP ODS that delivers energy to approximately 2.2 million locations for a population of around 4,2 million people. The peak power of the Croatian power system is around $3100 \mathrm{MW}$ and total consumption is around $17 \mathrm{TWh}$.

Due to this specific geography and historic development, Croatian transmission system backbone (220 kV and $400 \mathrm{kV}$ lines) are built in two main directions: east-west and north-south as shown in Figure 2 with red and green lines. These main lines are shared between four system segments called "transmission areas" - eastern area (Osijek), central area (Zagreb), western area (Rijeka), and southern area (Split). Furthermore, as can be seen, thermal power units are mostly located in the central north part of the country and make almost half of the installed capacity. On the other hand, almost all hydropower plants are situated in the southern part of the country, near the Adriatic Sea. In that line, most of the existing, as well as most of the future solar and wind power installations are located in the southern regions as will be shown in Section 3.

The electric power system of Croatia manifests very big seasonality, with the southern regions having high peaks during the summer touristic season. Most of the electricity generation comes from hydroelectric power plants (around $40 \%$ to $50 \%$ ) which are located along the coast and in the northern region. Somewhat less electricity (20\% to $30 \%)$ is generated from thermal power plants which are located in the northern and eastern region and a part of electric energy comes from nuclear power plant Krško which is located in Slovenia, but close to Zagreb, the Croatian capital. The installed capacity of thermal and hydro is approximately the same, around $2000 \mathrm{MW}$.

The Croatian system has very high interconnection capacity and the level of import is around $20-30 \%$ of total energy consumption. The current installed wind capacity is around $800 \mathrm{MW}$ and solar is around $90 \mathrm{MW}$ that together generates around $15 \%$ of the remaining electricity generation. The current share of solar PVs is significantly smaller and mostly achieved by smaller PVS installation $(<1 \mathrm{MW})$ and low-voltage installation, but that is expected to change soon with the number of big solar projects increasing in numbers as will be shown in the following section of this paper.

Besides modeling electricity generation, it is important to distinguish electricity consumption specifics. The electricity-intensive industry is located mainly in the northern part of Croatia, near the large thermal power plants. On the contrary, the coastal part of Croatia is less industrialized, and the foundation of development is mainly tourism. This has an unfavorable impact on the Croatian power system since tourism is a seasonal activity that results in extremely high electricity demand during the summer and extremely low electricity consumption during the winter months. Summer peak demand is several times higher than demand in the winter period. Such seasonality affects characteristic power 
flow direction in each season. Because of relatively small loads and considerable RES production, especially during the night, long overhead lines, and lack of voltage regulation nodes, voltage levels in southern Croatia vary a lot and even exceed the upper voltage limits. Without any rigorous definition, this type of network can be referred to as the "weak grid" [29]. In [30] the authors address the problems of connecting RES to a weak grid very generally and it is concluded that every system has its specifics similar to [8]. These problems will soon be manifested since wind power plants integration was significant in the year 2020 with even more plants expected soon (Figure 3).

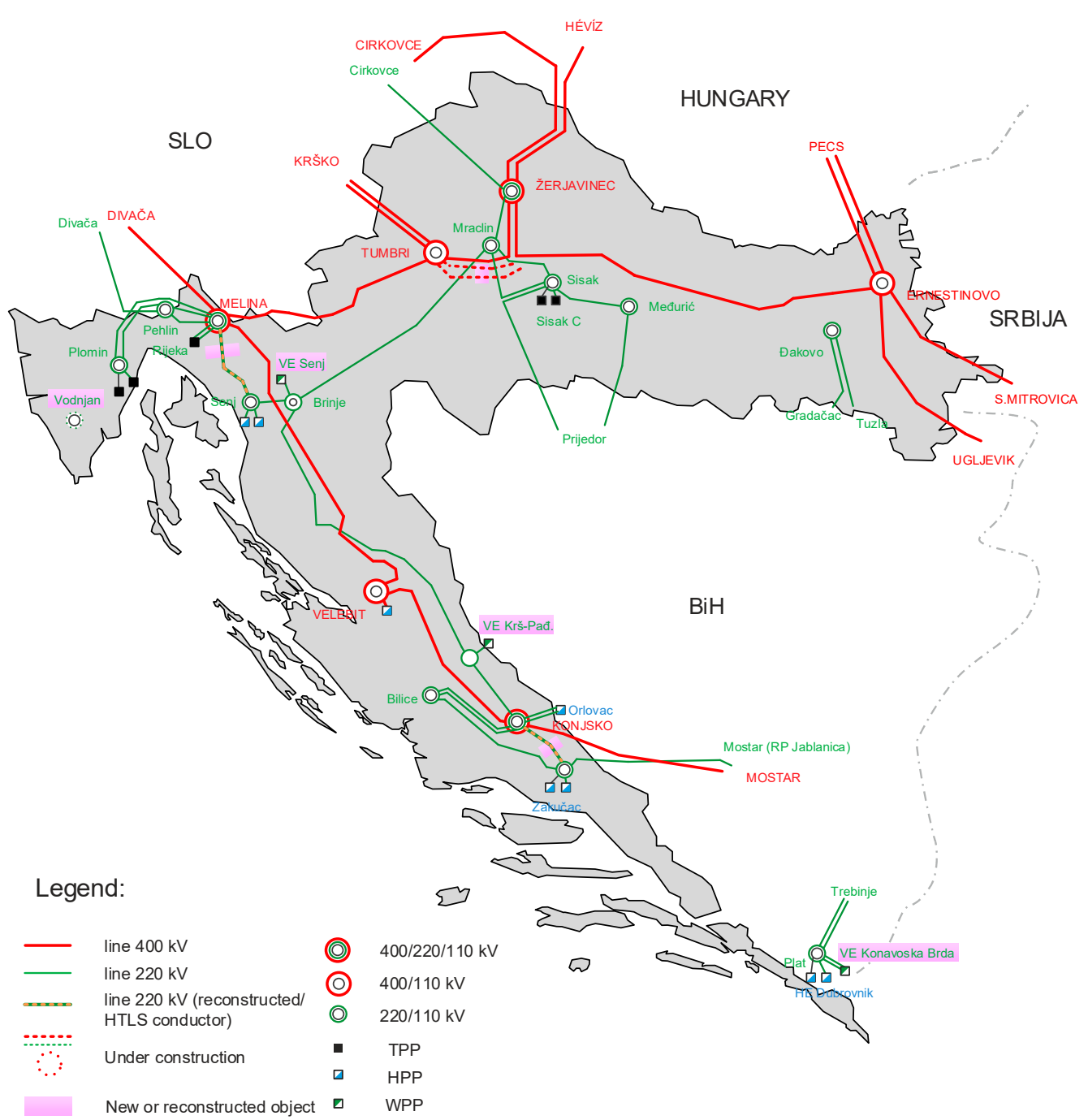

Figure 2. Croatian high-voltage $(220 \mathrm{kV}$ and $400 \mathrm{kV})$ transmission system with its biggest production units (hydro and thermal).

The main document and analysis that estimates the costs and connection scenarios is called EOTRP — which translates to "optimal connection study" [31]. It contains an analysis of the steady-state power flows and short circuits. The document considers technical possibilities for carrying out the connection, calculates the connection charge following the rules on the charge for connection to the electric network, as well as the increase of connection power which are embedded in the legislation regulating the power system activities. The approach that is currently still applied regarding the cost distribution can be summed up as the "deep costs". The entire investment is defined as the investors' obligation since the deep connection policy dictates that the investor is the one paying for any reinforcement or reconstruction of the grid caused by his connection [32]. When 
considering a specific new RES project all other projects that are currently in consideration or have already acquired required connection permit can result in higher costs since not only current capacity but also this expected capacity is considered. The analysis is conducted for a wide range of scenarios ranging from low production, high demand scenarios to high production, low demand scenarios which usually prove to be limiting. Several thousands of MW in potential new renewable energy projects are planned in the next ten years, mostly in the southern regions as was already identified. This will put enormous strains on the existing infrastructure, thus significant investments into new strategic transmission capacities will have to be done to ensure system adequacy and paths for evacuating all the energy generated from renewable sources. Another issue is the reduction of grid inertia as more and more converter-interfaced renewable energy sources are commissioned. Although the Croatian system is well interconnected with the rest of Europe, such inertia reduction following increased RES capacity shares exceeding the total peak power of the system is expected and will soon have a continent-wide impact.

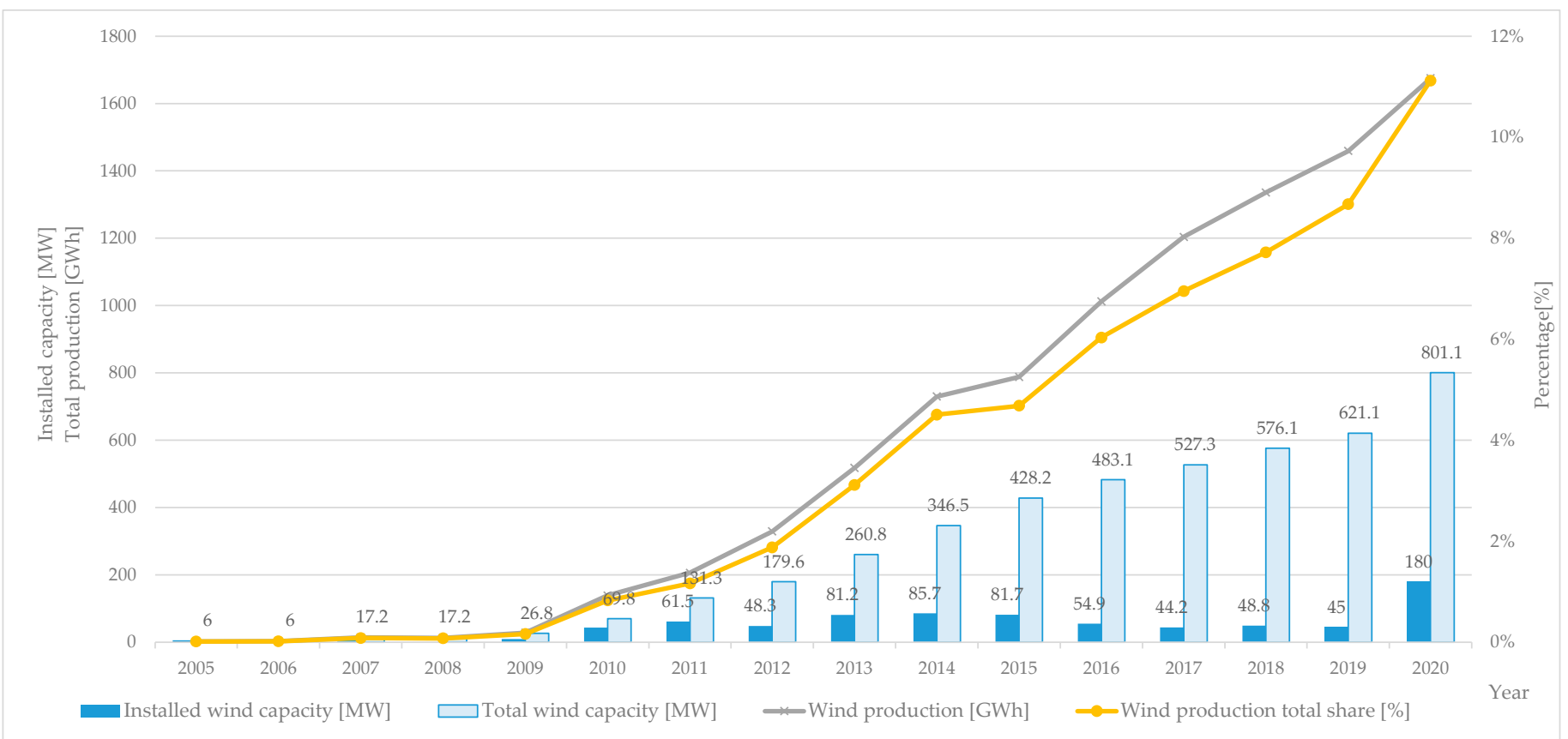

Figure 3. The integration level of wind power plants in the last 15 years-Croatian energy system.

\section{Analysis of RES Integration Future Scenarios and Inertia Reduction}

\subsection{Expected Large-Scale RES Integration}

In the next 10 years, i.e., from 2020-2030, a large increase in the integration of wind and solar power plants into the Croatian electric power system is expected. Over $6 \mathrm{GW}$ of RES power is planned to be integrated into the system. This section provides a systematic analysis of the specifics of RES integration concerning voltage level, transmission area, annual growth, etc. First, the future RES capacity analysis regarding geographical location, i.e., the transmission area was done. As Split and Rijeka areas are located on the Adriatic coast, while Zagreb and Osijek are continental areas, almost all RES capacity is integrated into Split and Rijeka transmission areas. This distribution of RES integration is shown in Figure 4. PV integration dominates in the Split area, while WPP integration dominates in the Rijeka area. 


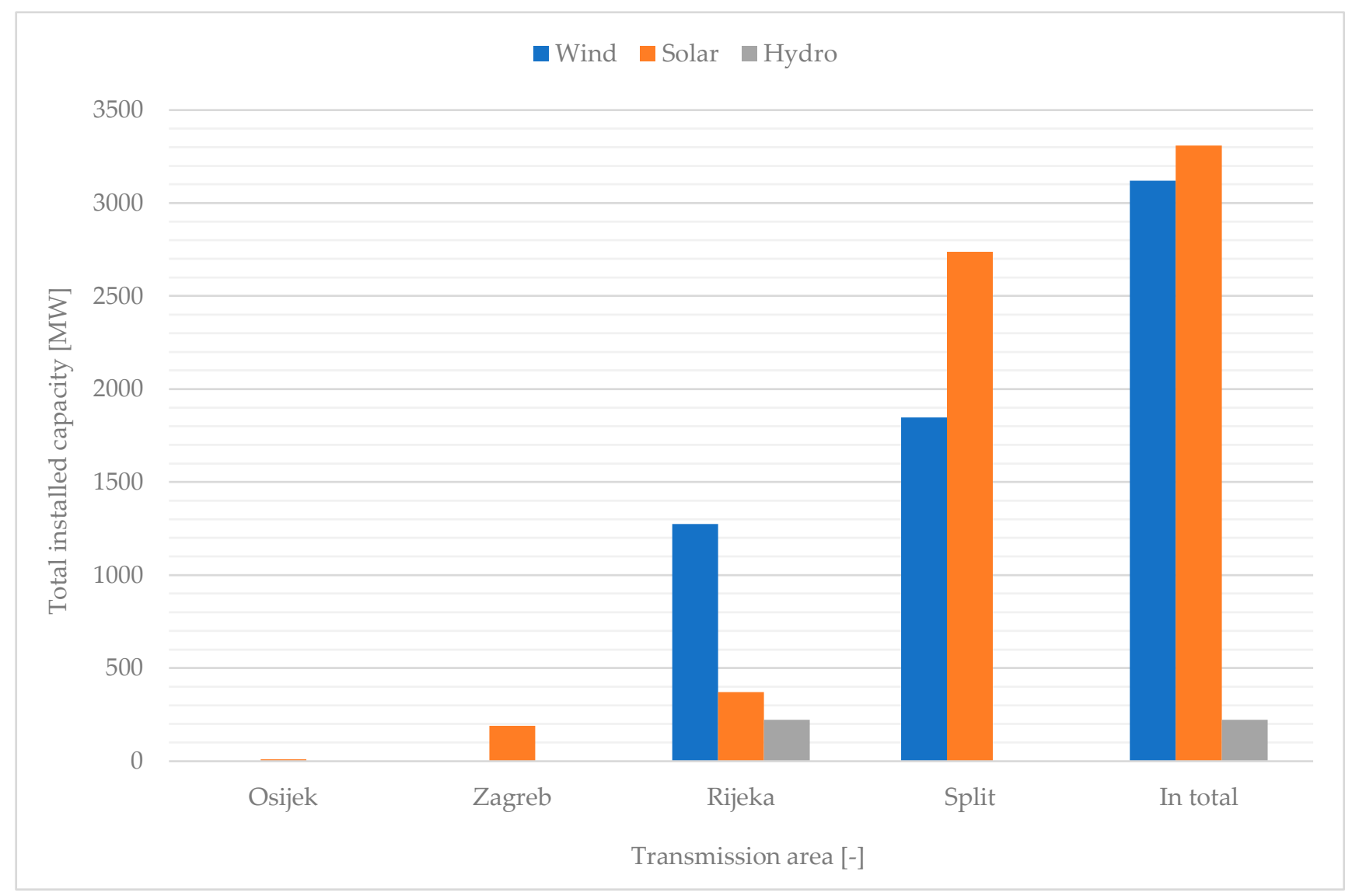

Figure 4. Total planned capacity in the period 2020-2030 divided by transmission area of the Croatian power system.

If the voltage level is considered, it can be said that so far RES had mostly been installed at the $110 \mathrm{kV}$ voltage level. However, in the coming years, a large share of RES capacity is planned to be integrated into the $400 \mathrm{kV}$ voltage level while only a small share of the total capacity of RES is expected to be added to the $220 \mathrm{kV}$ network. This is due to ENTSO long-term plan to have just a $400 \mathrm{kV}$ network as the primary voltage level. It is also worth mentioning that numerous small WPPs and PV systems are planned to be integrated into the distribution network, but their total power is less impactful compared to RES capacity at the transmission level but sums up to almost $500 \mathrm{MW}$ of possible capacity in the coming three-year period. Figure 5 shows the distribution of RES integration concerning the voltage levels.

Regarding the expected dynamics of the integration of new potential capacities, Figure 6 presents the realized dynamics in the years 2010-2020 and expected installation year for future projects. It can be seen that the installed capacity of RES will exceed the 3200 MW level which is the peak demand of the Croatian system approximately in the year 2023. The prediction of future total planned RES capacity is based on the available data from the TSO development plans and grid connection study procedural data as well. The predicted years of plan realization were estimated according to the information available to the authors, given that this data is not publicly available. The number of RES integration projects is large, but according to the current statistics on the implementation success of applied projects, the expected project implementation number is about one-third of the total number of applied projects. Additionally, the period needed to integrate these projects will probably be longer than 2030 . 


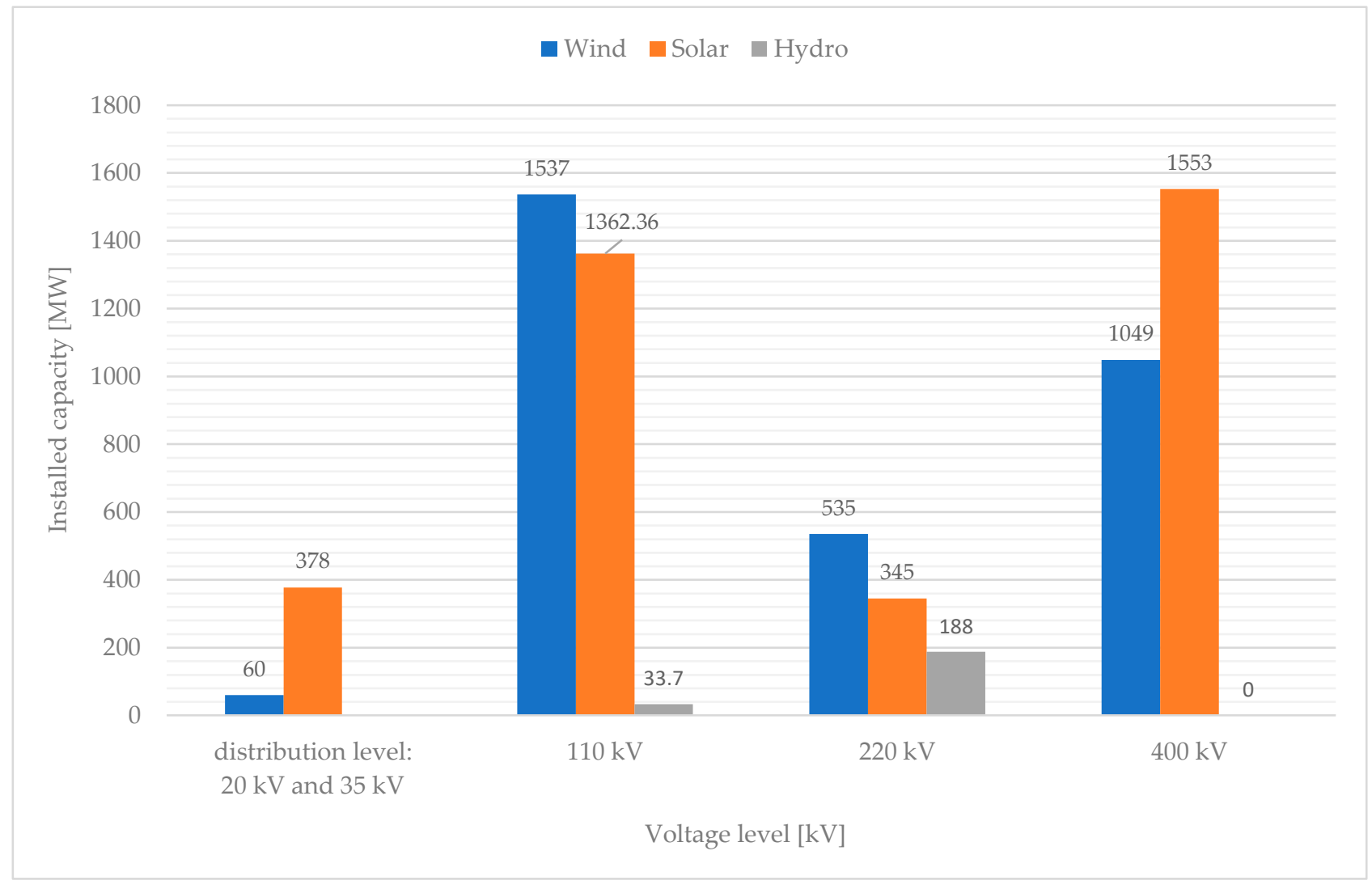

Figure 5. Total planned RES capacity in the period 2020-2030 divided by voltage levels.

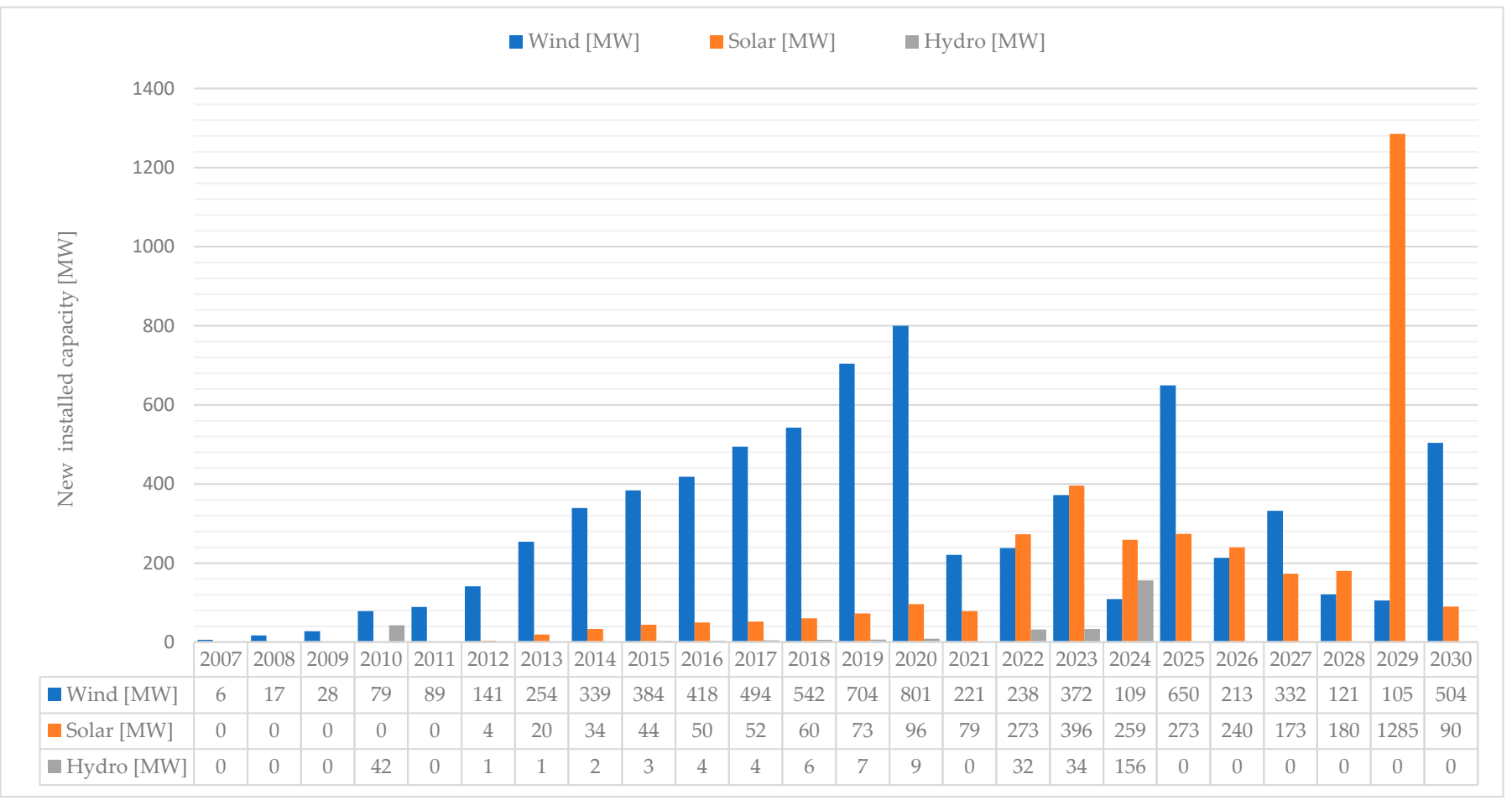

Figure 6. Total planned RES capacity in the period 2020-2030 yearly expected dynamics of capacity increase. 


\subsection{System Inertia Reduction Scenarios}

To assess the general impact of large-scale integration of RES in the Croatian power system reduced power system model shown in Figure 7 was developed using DIgSILENT PowerFactory software [33]. This is extended research of the author's previous paper [34]. It consists of four major areas as described in the previous section, concentrated around four major cities in Croatia: Osijek area (east), Zagreb area (central-north), Rijeka area (west), and Split area (south). The areas are radially connected through $400 \mathrm{kV}$ lines: east-north-west-south, while the generation and loads in this model are interfaced on the $110 \mathrm{kV}$ level equivalents since most of the energy exchange between the distribution and transmission is done on the interface of transmission stations of $110 / x$ voltage levels.

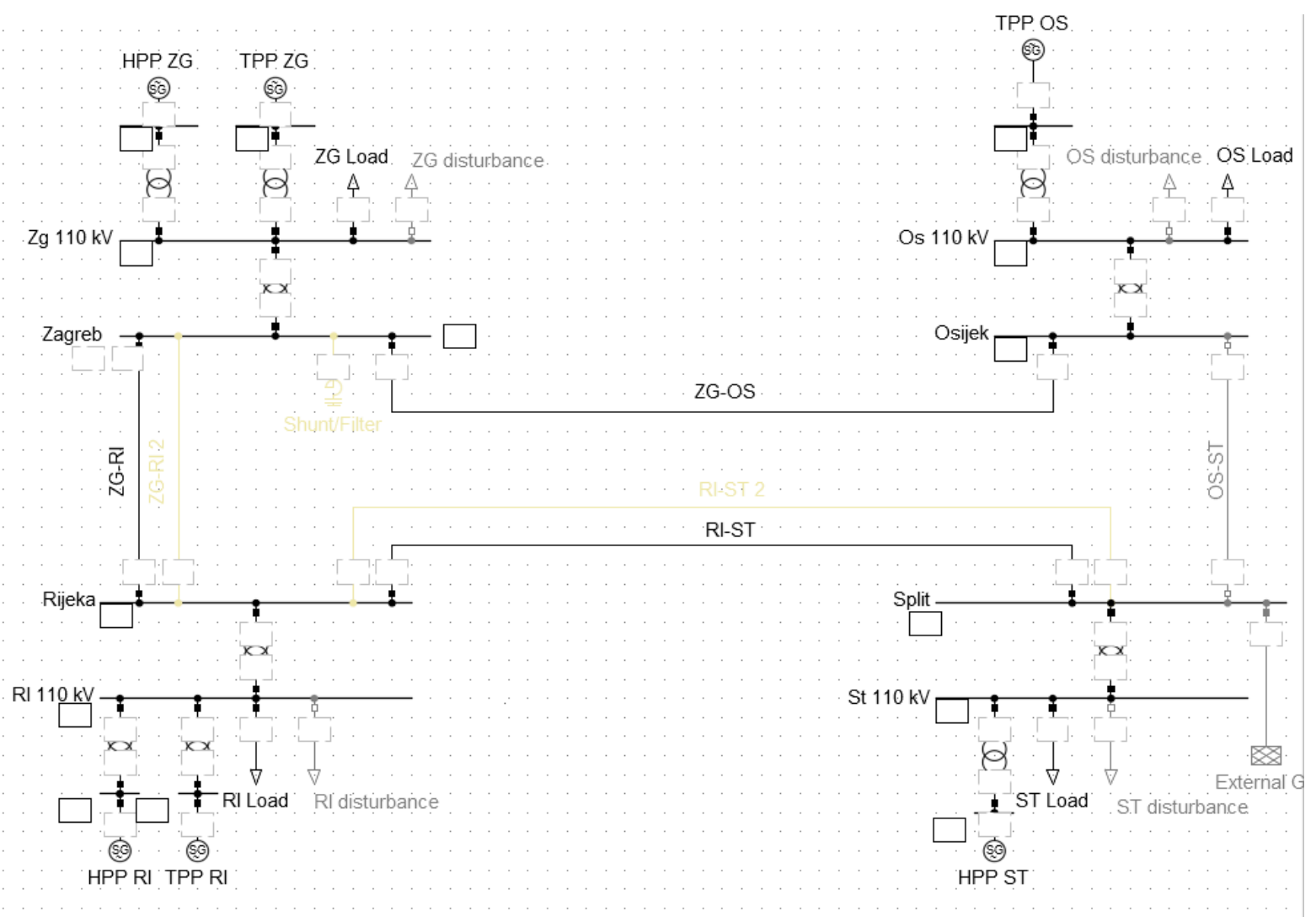

Figure 7. Reduced system model of the Croatian power system.

The base case scenario that reflects the situation in 2020 consists of $20 \%$ online converter-connected renewable energy capacity (excluding small hydro) and this share is increased in steps of $5 \%$ to investigate the impact of inertia reduction on frequency dynamics and stability. Real power plant data is used in the model but is not listed here due to confidentiality reasons. Estimation of system inertia reduction between $20 \%$ and $50 \%$ RES share is shown in Figure 8. It can be seen that the inertia reduces linearly as the share of RES increases. The inertia of the Croatian system in the future will be further reduced on account of thermal units decommission. Decommissioning of hydro units is highly unlikely in the future and it is also important to note that the thermal portfolio will not be completely decommissioned as thermal power plants in the west, north, and east are also used for district heating. Spatio-temporal inertia reduction is possible in the future on the account of offline hydro units, but this is not considered in this paper. From the simulated case studies, an approximately $30 \%$ increase of RES share will result in almost $40 \%$ inertia reduction. 


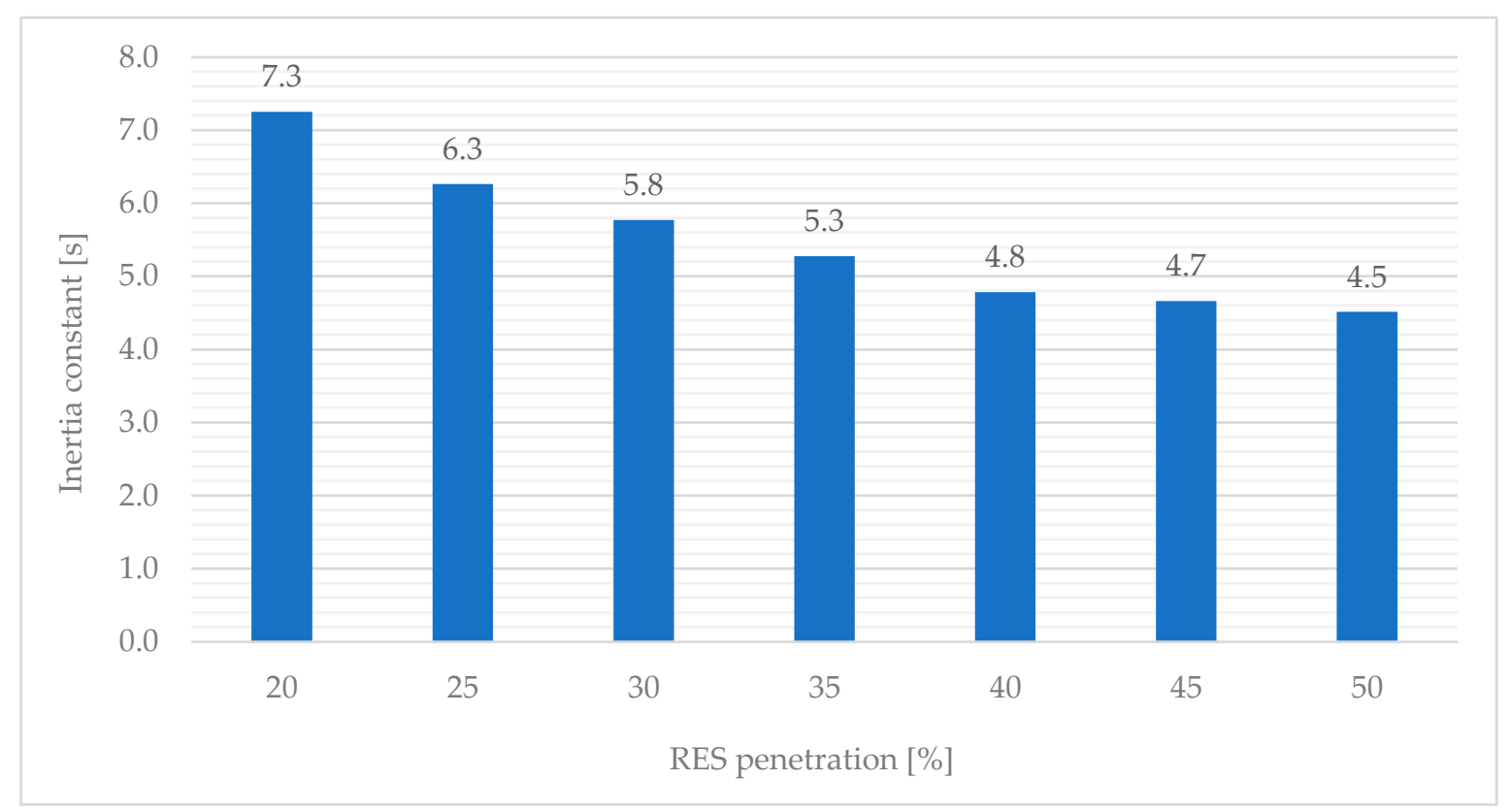

Figure 8. Inertia constant interdependency with RES share.

Figure 9 shows the estimated system frequency response for a $300 \mathrm{MW}$ disturbance in the Zagreb area (north). Several phenomena can be observed: firstly, as the inertia decreases the rate of change of frequency increases which will have consequences for system protection settings (ROCOF relays). Secondly, frequency nadir increases which means the under-frequency load shedding schemes will be triggered sooner if not retuned. Finally, oscillations increase with the increase of RES which reduces the system stability as critical modes move toward the y-axis in the complex plane (eigenvalues).

As more and more converter-interfaced RES is integrated into such a system that is: (a) radial and (b) where generation and load centers are distanced, the transmission capacities must be increased. In the shown case, the south-west and west-north high voltage backbones must be strengthened (Split to Rijeka and Rijeka to Zagreb). Otherwise, the lines are congested or even overloaded which hinders the evacuation capabilities from south to north, as shown in Figures 10 and 11. Without increasing transmission capacities, the line from Split to Rijeka is congested, while the line from Rijeka to Zagreb is overloaded. This also negatively affects the voltage profile and voltage stability as is visible in Figure 10 due to high loadings of lines, the voltage drops are significant and voltages in the network are below 1 p.u. Increasing transmission line capacities (Figure 11), the congestion and overloading issues are solved and the voltage profile is healthier and closer to the nominal operating range which also increases the voltage stability margin. 


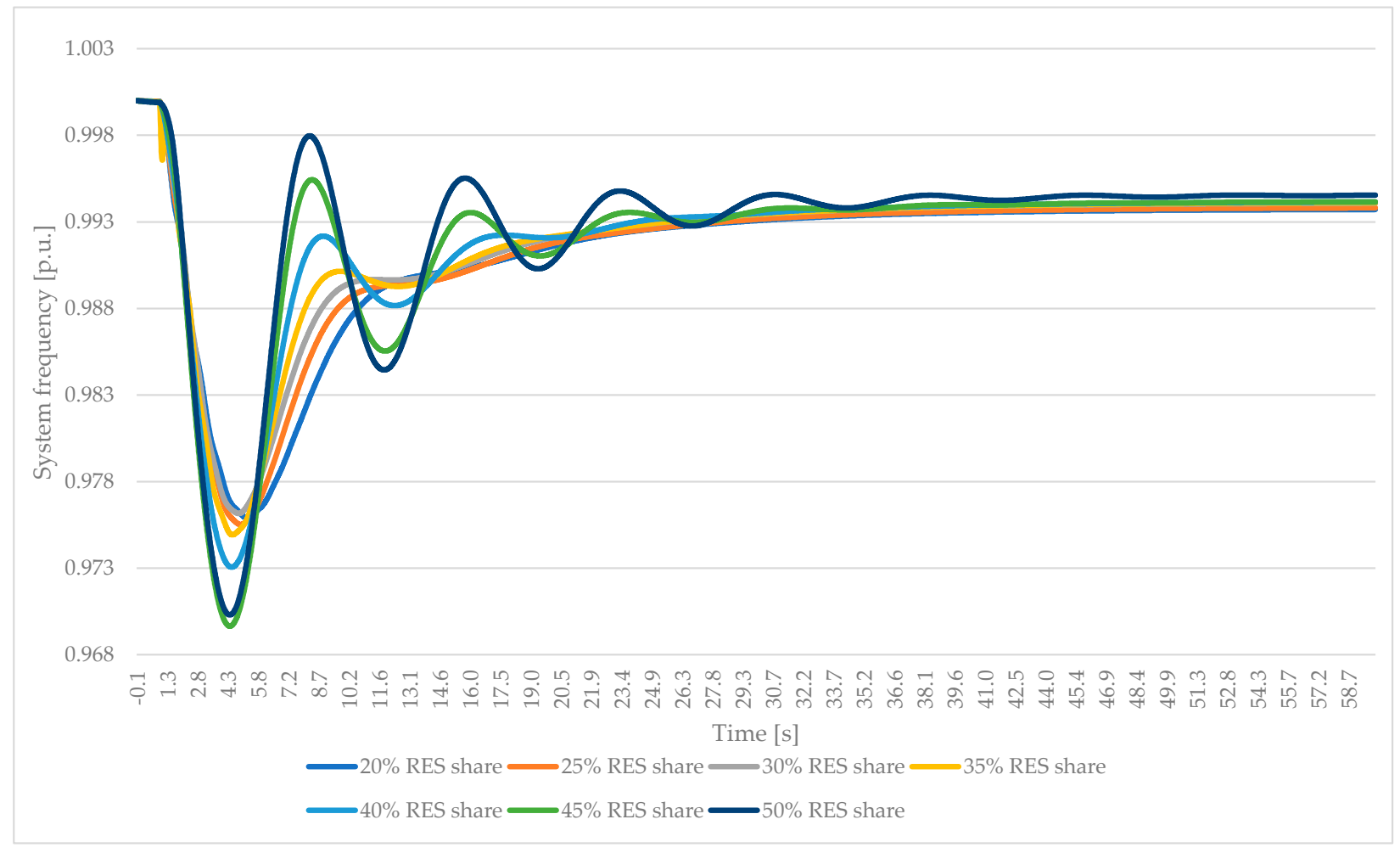

Figure 9. Frequency response for different shares of converter-interfaced RES.

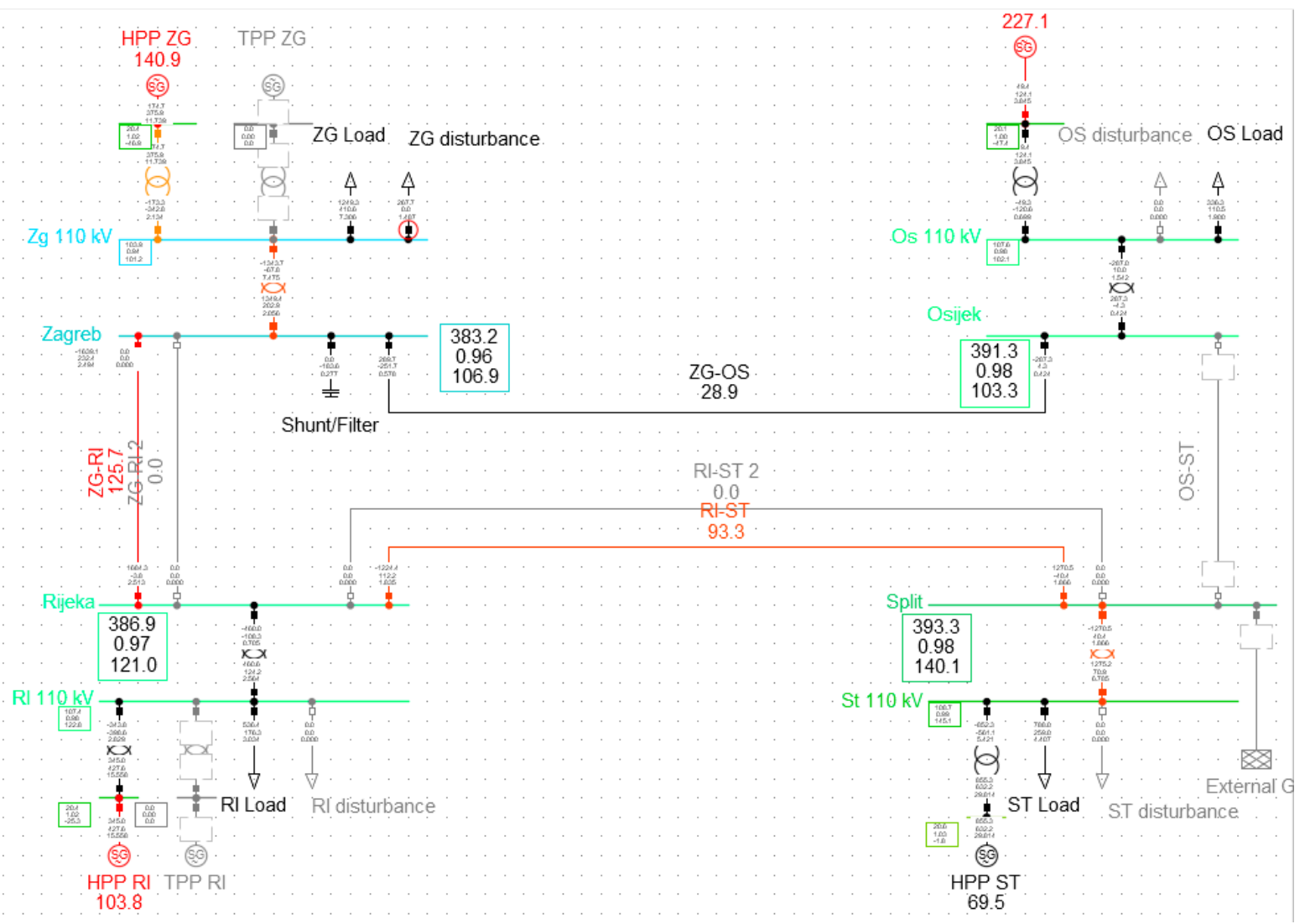

Figure 10. Line loadings and voltage profile without increasing transmission capacities between north and south. 


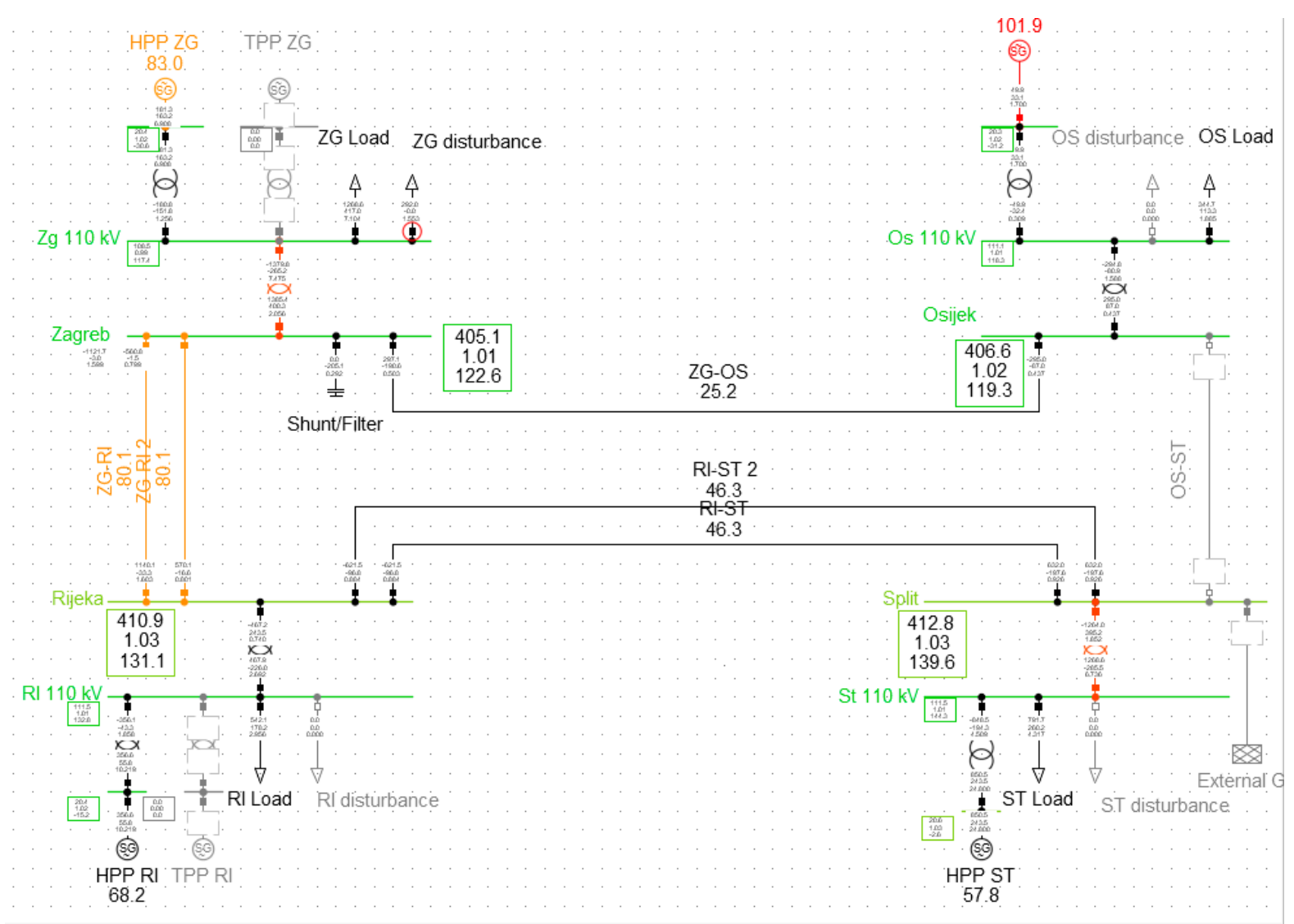

Figure 11. Line loadings and voltage profile with increased transmission capacities between north and south.

The conducted analysis shows Croatian system has many challenges to overcome to accommodate a large number of new RES projects. From the transmission capacity increase between north and south to reduce the impacts on the voltage stability margins and steady-state loadings, through reduction of inertia and reserve capabilities due to converter interface of RES that could jeopardize the frequency stability. Therefore, ROCOF and under-frequency load-shedding relays will have to be retuned and it will be necessary for new RES units to participate in system frequency control through mechanisms such as virtual inertia and deloading [35]. More advanced strategies such as grid-forming virtual synchronous machine schemes are also very promising [36] but are not in the focus of the paper.

\section{Further Challenges of Photovoltaic Systems Integration}

As presented in the previous sections, a large increase in photovoltaic system (PVS) integration is expected in the Croatian EPS soon, almost $3 \mathrm{GW}$, so this section will present the main challenges and problems posed by large PVS integration. The increase in PVS integration negatively affects the system frequency stability of the power system because, on the one hand, they replace conventional synchronous generators which leads to a reduction of the rotating kinetic energy of the power system, while on the other hand, the way PVS are connected to the network, via power electronics, makes them insensitive to system frequency changes. Croatian system frequency control consists of three levels, primary, secondary, and tertiary control, but PVS mainly affects the inertial response phase and primary frequency control.

1. Inertial response

Since PVS does not have rotating parts that could reduce or increase their kinetic energy, PVS does not inherently contribute to the inertial response. This could potentially result in the appearance of higher values of ROCOF in the power systems with a high share 
of the PVS production. Additionally, by displacing a share of the thermal power plants with the PVS, the system inertia constant highly reduces as shown in Figure 8. The system inertia constant directly affects the value of ROCOF and the frequency minimum during the load disturbance.

\section{Primary frequency control}

As PVS normally operates to produce maximum power, i.e., in the maximum power point tracking (MPPT) mode, this means that in the event of a frequency drop they cannot produce the additional required power. However, in the event of an increase in system frequency, PVS could reduce their production and thus contribute to the primary frequency control. The previously mentioned fact that PVS in the power system replaces conventional power plants negatively affects the primary frequency control as well. One reason is that the total reserve power required to ensure the satisfactory action of the primary frequency control is reduced. The other reason is the increase in the total equivalent droop of the system (the combined effect of the droop of all generators' speed governor) which is manifested in the increase of the system frequency deviation from the nominal value in the temporary steady state that occurs after the primary frequency control phase. Besides, if PVS does not participate in the system frequency control, this further increases the required flexibility requirements of the remaining conventional units which, due to reduced system inertia, need to provide a faster response. Additional problems are sudden changes in environmental conditions and shading of the PVS modules because under such conditions a sudden change in the power output of the PVS could occur.

To mitigate these negative effects on the system frequency stability, PVS should participate in the system frequency control. The paper [37] brings a detailed survey of PVS possibilities to participate in various ancillary services. The most commonly used method for enabling PVS participation in the system frequency control is to force PVS to operate at the point below than a maximum power point, in the so-called deloaded mode. In that way, a specific amount of power reserve is maintained and can be injected into the grid in the case of load disturbance. The concept of the PV deloading process is shown below (Figure 12).

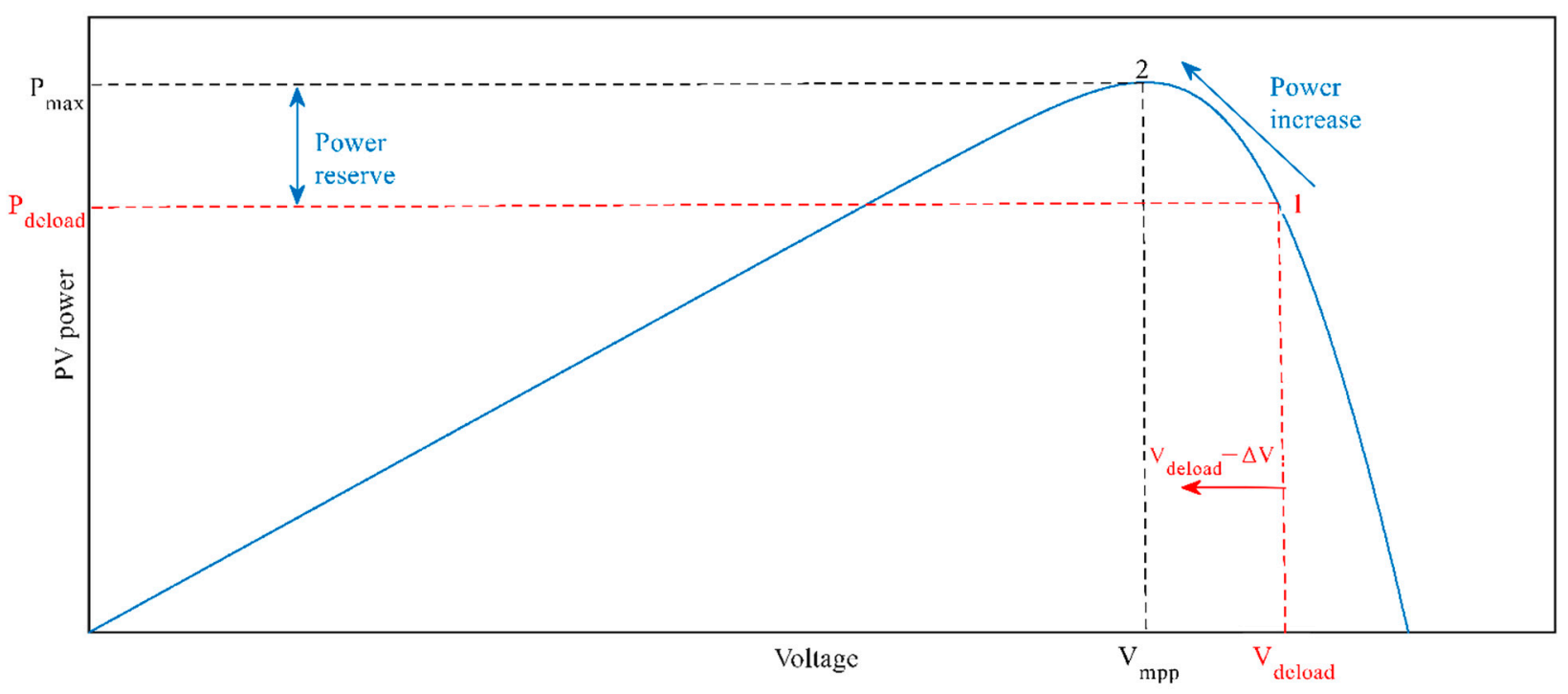

Figure 12. PV deloading process.

By increasing the voltage $V_{\mathrm{mpp}}$, corresponding to the voltage at the point of maximum power, to the value $V_{\text {deload}}$, the PVS is forced to operate at the sub-optimal point and a certain amount of power reserve is provided. Similarly, by decreasing the voltage $V_{\text {deload }}$ for $\Delta \mathrm{V}$, the maintained power reserve is released to the grid.

The PV power reserve can be maintained in a few ways [38]: 
(a) absolute production-PVS produces a fixed amount of power;

(b) delta production-PVS produces a certain percentage of power regarding the available maximum power.

However, the paramount question here is what amount of power reserve needs to be controlled. A model for PVS reserve allocation to improve system frequency response is proposed in [39]. The larger the power reserve, the greater the losses, but also the greater the PVS contributions to the system frequency control. Therefore, the tradeoff between the desired contributions to the system frequency control and the losses should be defined. The paper [40] shows what amount of power reserve PV should maintain to provide a satisfying frequency response for the power system. The method presented in [35] is based on a parabolic approximation of the system frequency response. An explicit mathematical function of the frequency nadir is established depending on the system inertia and PVS power reserve. In this way, the analysis of the PVS power reserve impact on the frequency nadir can be performed. Thus, when PVS participates in system frequency control, using this approach the required minimum PVS power reserve can be determined to maintain a satisfying frequency response. The required amount of PVS power reserve is determined regarding a certain decrease in the inertia constant.

Recently, the integration of PVS into the Croatian electric power system is growing rapidly and a share of $20 \%$ of PVS production in covering daily demand can be expected very soon. It should be noted that PVS do not currently participate in frequency control in Croatian EPS due to the still relatively small installed capacity. However, if a share of $20 \%$ of PVS production is analyzed by applying the method from [40], the result shows that the calculated minimum required amount of power reserve for Croatian EPS does not exceed $3 \%$ of nominal PV power as shown in Figure 13. In this case, it is assumed that the inertia constant reduces by $20 \%$ (red line in Figure 13).

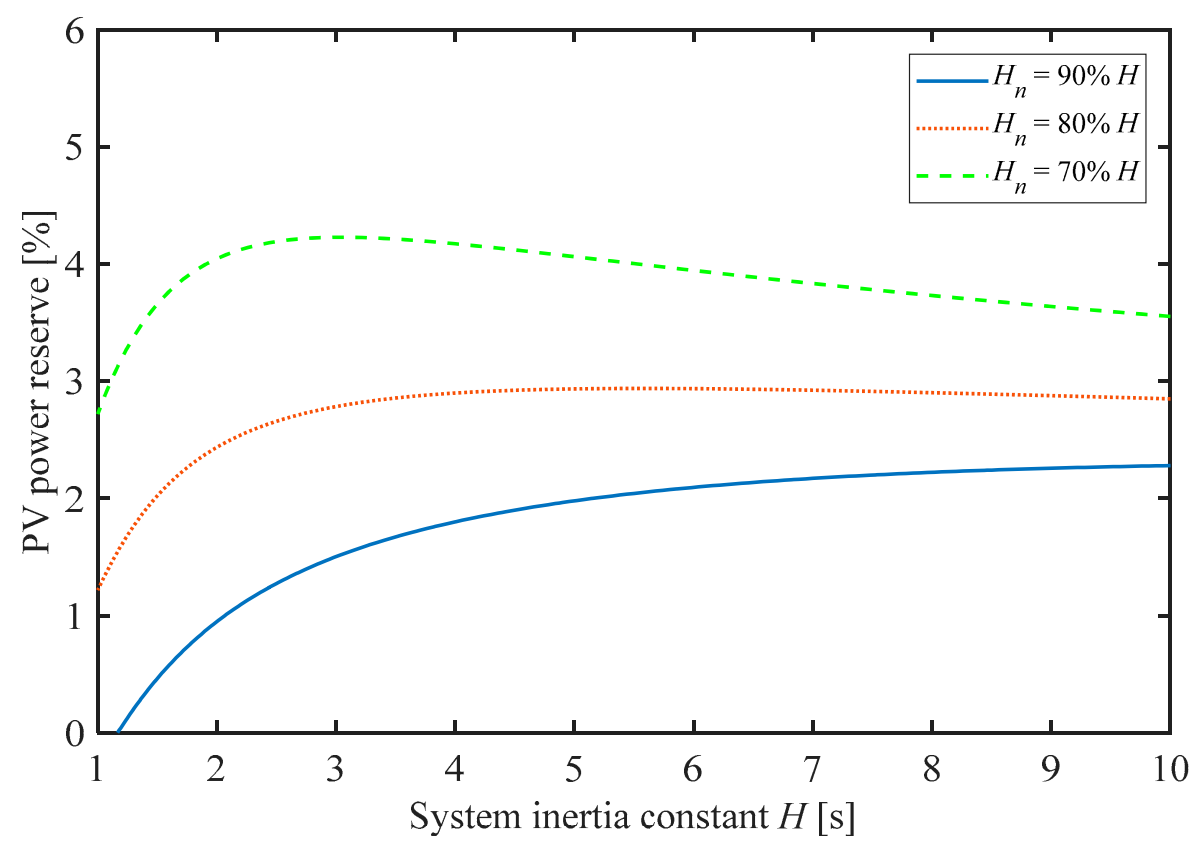

Figure 13. Required PV reserve minimum for Croatian EPS.

Moreover, the ROCOF analysis can be performed regarding the obtained required values of the PV power reserve. However, if the typical droop control method is applied to the PVS to enable them to participate in the system frequency control, then PVS has no effect on ROCOF at $t=0^{+}$as this value depends mostly on the average system inertia and the size of the occurred imbalance. Accordingly, ROCOF is observed and calculated at $t=100 \mathrm{~ms}$ although, generally, the analysis could be performed for any moment. 
Figure 14 shows the comparison of the ROCOF, following a disturbance $P_{L}=0.05$ p.u. (around $150 \mathrm{MW}$ for the Croatian EPS), for three different situations: a base case (green), a case with connected PVS to the power system but without participating in system frequency control (blue), and a case of PVS participating in system frequency control (red). The second and third cases are examined for a $20 \%$ reduction of the system inertia constant regarding the system inertia of the base system. It is assumed that a thermal power plant of $300 \mathrm{MW}$ is replaced by PV power plants. The maintained PV power reserve is $3 \%$ of the nominal PV power. At the bottom right of Figure 14, the magnified view of ROCOF is shown for the normally expected system inertia constants. It can be seen that replacing the conventional power plants with the PV power plant leads to the ROCOF increase of approximately $100 \mathrm{mHz} / \mathrm{s}$ and an even greater increase for lower system inertia constants, but the participation of PVS in the system frequency control can significantly reduce the ROCOF. It can be concluded that by de-loading the PV power plant, the ROCOF at $t=100 \mathrm{~ms}$ can be improved but it's still worse than it was before the connection of the PVS to the power system. However, by increasing the amount of PVS power reserve, the ROCOF at $t=100 \mathrm{~ms}$ can be even better than it was before connecting the PVS to the power system.

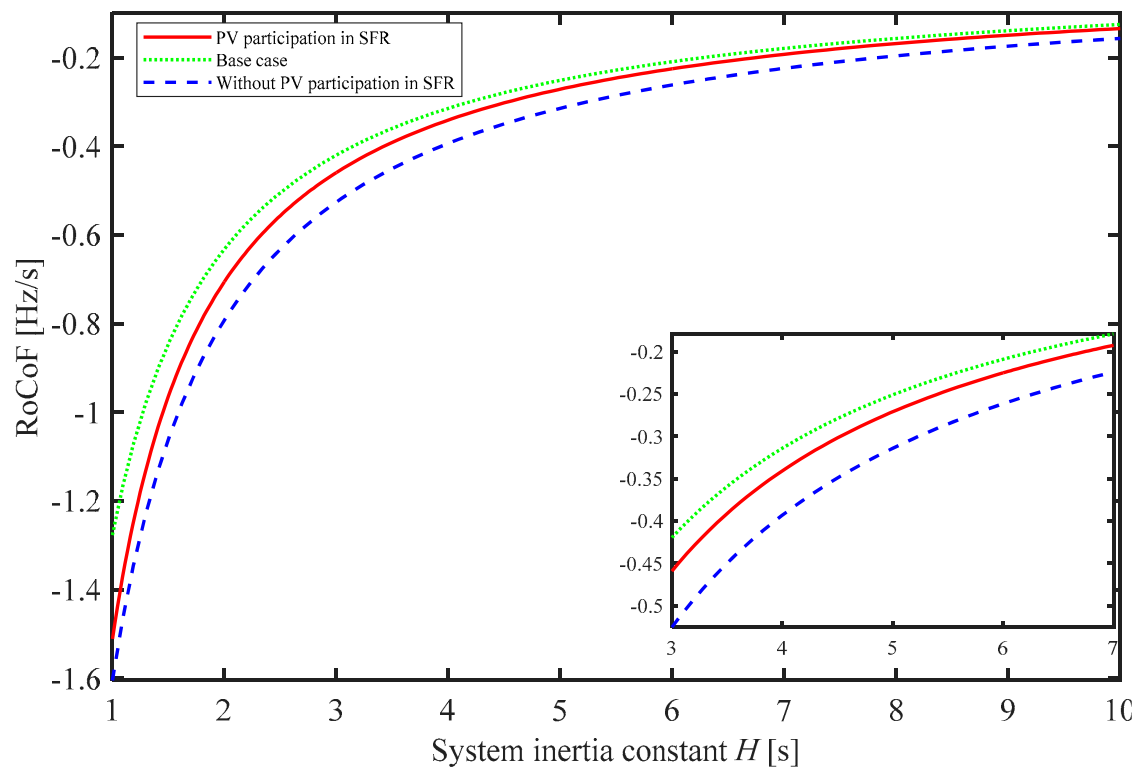

Figure 14. ROCOF analysis regarding the calculated required minimum PV power reserve.

\section{Further Challenges of Wind Power Integration}

RES are highly dependent on input stochastic variables such as solar radiation, wind speed, temperature, air pressure, river inflow, etc. Predicting the expected power output of RES plants based on those variables is difficult and their output power can change causing imbalances. Accurate prediction of WPP power output is crucial for both power system operators and for WPP itself. In a low-carbon energy system, a transmission system operator must design requirements for balancing services based on future demand as well as future WPP generation. Improving forecasting techniques brings lower reserve requirements entailing lower overall system operational costs.

When it comes to balancing, each market player in Europe is balance-responsible meaning that it must pay for all imbalances it causes. With more accurate forecasting, WPP pays lower imbalance penalties to the TSO. Along with the lower imbalance costs, with correct forecasting DER/DGs get an opportunity to sell ancillary services to the operators. When forecasting accuracy is low, they risk the possibility to be unable to deliver contracted service which brings new penalties. 
Developing procurement processes for ancillary services with shorter gate closures is one of the main tools to decrease requirements as WPP forecasting is far more accurate in shorter terms. One of the processes worth mentioning is balancing mechanisms in Europe where flexibility could be provided up to one hour before delivery. Such short gate closure means that if WPP has high forecast error such that more output power is possible than initially forecasted, the WPP could sell surplus power as an ancillary service. The analogous conclusion applies if there is less output than initially forecasted when WPP must sell imbalance before delivery or pay imbalance costs after delivery.

\subsection{The Importance of Power Production Forecasting}

Energy production from renewable sources (RES), of which a large share is made up by production from wind farms (WFs), will have an increasingly significant impact in achieving low-carbon development of the energy sector due to its continuous penetration into electric power systems (EPS). Although wind farm integration brings many environmental benefits, the unpredictable and volatile nature of wind generation poses many challenges for power system operators (e.g., economic dispatch of power plants, dynamic system stability, etc.), electricity market operators, and energy producers and traders. One of the possible solutions to these challenges is the development of advanced tools and methods for reliable short-term forecasting of wind production [41]. In addition to the above, long-term production forecasts can be used for planning the maintenance of generating units and other components of the power system, but their accuracy is significantly reduced for time intervals greater than 5-7 days in advance [42]. The most significant application of short-term forecasting of wind power production is manifested in the reduction of balancing energy requirements, i.e., power reserve, which is necessary to cover the deviations of wind generation from the contracted schedule [43].

The main purpose of forecasting methods is to provide insight into expected wind speeds and production from over minutes, several hours, or days, depending on the user's needs. Production forecasting methods can generally be divided into two approaches. The first approach (statistical) is characterized by forecasting using statistical models, trained on large amounts of measured historical data (SCADA) and weather prediction data (Numerical Weather Prediction-NWP) as the input data for statistical model development. The second approach (physical) consists of methods that use meteorological forecasts as the input data in a detailed WF physical model consisting of the wind farm characteristics (turbine layout, terrain, production characteristics of wind turbines, etc.). The use of the physical characteristics of the terrain and wind turbines makes the basic difference between the two approaches. Various combinations of these approaches, which take advantage of individual methods, are often classified in the literature as hybrid (combined) approaches.

\subsection{Application of Advanced Deep Learning Methods on WPF}

According to the form of available input data that can be used for forecasting production from wind farms (sequential forecasts of atmospheric conditions from meteorological models) and realization of production from the SCADA system, a sequence-to-sequence problem can be formulated: mapping of weather forecast sequences (mainly wind speed and direction) on sequences of wind power production. During the training and validation of the model, available predictors (in this case wind speed and direction) are used, which are mapped to the realized production of the considered WFs. The difference between the training and validation process is that during validation, the parameters of the neural network (weights) are not adjusted. During testing, new non-used data is inserted into the model, and the model provides a forecast based on the 'learned' relationship between the predictors and wind power forecast.

Before creating a deep learning model, it is necessary to prepare input data, which are usually not in a suitable format for model training. Preparation requires data purification (removal of outlier values, filling the missing values, etc.), time alignment of data (e.g., reduction to same time interval), and formation into appropriate data tensors. 
Models that are based on a special type of recurrent neural networks (RNN), especially long short-term memory (LSTM) networks are exceptionally successful in modeling long-term dependencies among meteorological variables and power production. Weather forecasts from numerical weather prediction models (NWP) provide time-labeled sequences of data suitable for recurrent network training. However, the accuracy of the LSTM based models significantly depends on model configuration and pre-training hyper-parametrization which is specific for each wind power plant. The process of training and testing the model on the actual two-year data of a wind farm in Croatia will be presented below.

Figure 15a shows the training and validation process of one deep learning mode. The model stops training when the loss function (mean square error-MSE) on the validation data does not change a certain number of epochs (e.g., 10 epochs). Figure $15 b$ shows the root mean square error (RMSE) between the predicted sequences and the actual values on the validation data, which is a validation metric for models in this case.

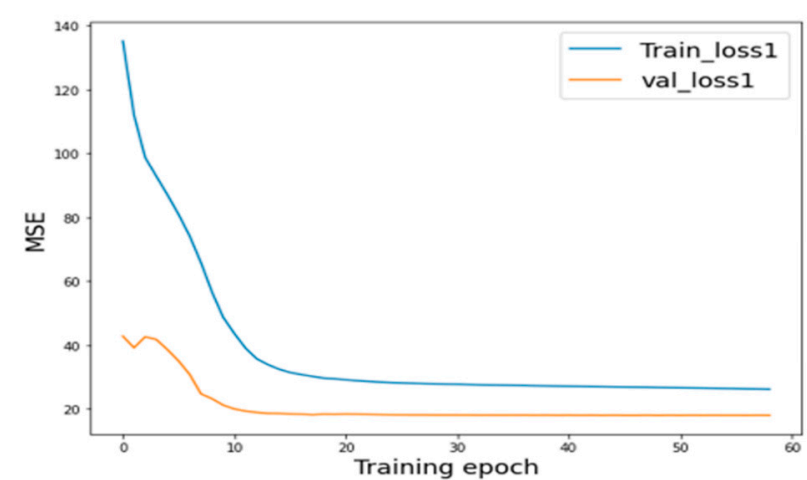

(a)

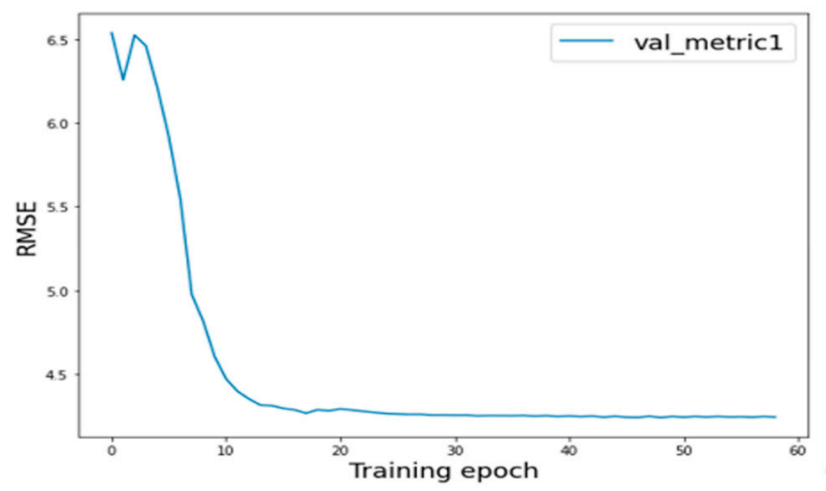

(b)

Figure 15. (a) Loss function reductions (MSE) (training and validation); (b) validation metric (RMSE).

Figure 16 shows an example of multiple model prediction trained on different predictors, in comparison to actual measurements from the SCADA system. Additionally, it is possible to plot confidence intervals of predictions, thus provide probabilistic wind power forecasting.

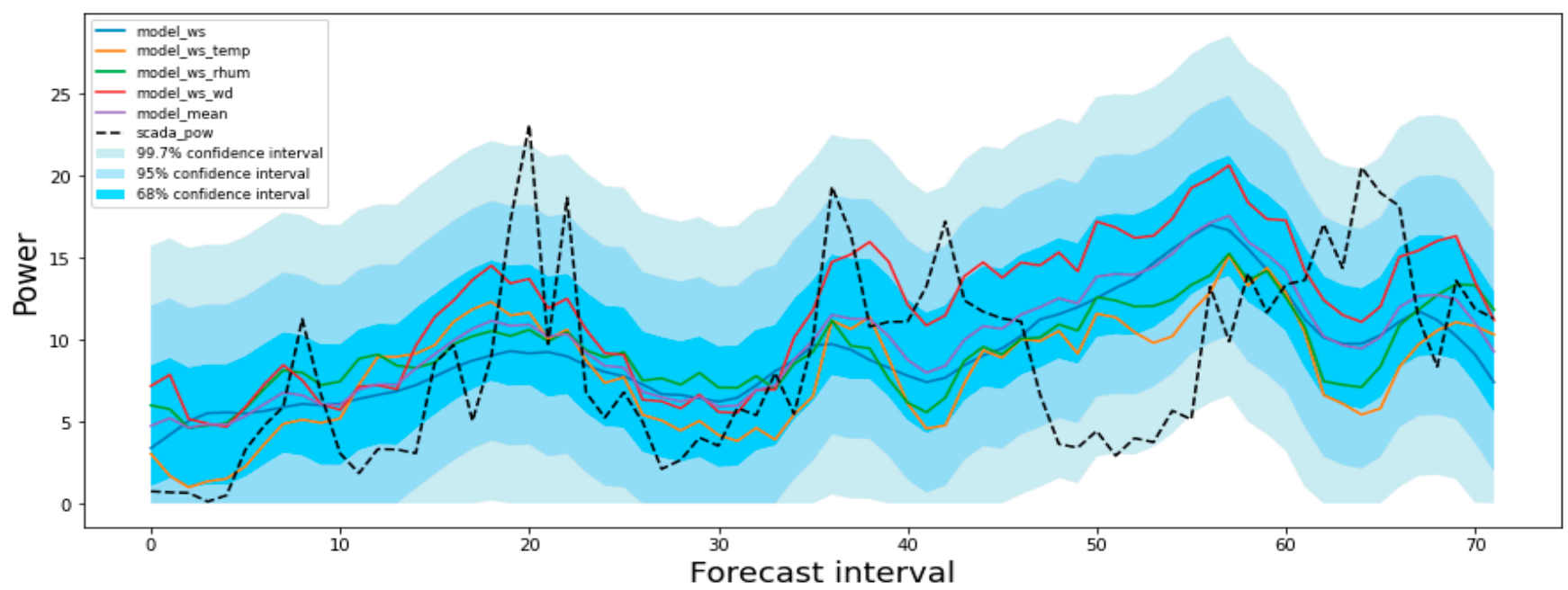

Figure 16. Confidence intervals and deterministic predictions comparison with actual values. 


\section{Conclusions}

This paper presents a comprehensive analysis of the Croatian EPS in the context of RES integration. In the last ten years, the installed capacity of wind power plants has increased greatly, from $80 \mathrm{MW}$ to $800 \mathrm{MW}$. In the next 10 years, in addition to further growth in wind power capacity, a great increase in solar integration is also expected. According to the available data, a total of about $6 \mathrm{GW}$ is expected in RES capacity to be installed into the system. Such a scenario even if $30 \%$ realized will inevitably affect the voltage and frequency conditions since the RES capacity would increase above peak power. Following that, this paper provides an insight into expected system inertia reduction and consequently, the effects that will reflect on the necessary changes in voltage and frequency control. Certainly, needed solutions will be to enable wind and solar power plants to participate in frequency and voltage control. Also, power production forecasting is becoming increasingly important to reduce and avoid unnecessary imbalances in production and consumption. However, a large interconnected $100 \%$ inverter-based power grid is not a realistic scenario soon because there will always be some large synchronous machines, usually hydropower plants, ensuring stability margin. Furthermore, there is a very real possibility that at certain points in the future there will be very little or even no synchronous generation, especially in islanded parts of the grid. This case is expected to be realized in Croatia by 2030. Therefore, it is imperative to design novel control architectures and methodologies and incorporate them into the system planning process so to ensure stable and autonomous operation of power grids with significantly reduced inertia.

Author Contributions: Conceptualization, N.H. and M.Z., methodology, N.H. and T.B., software, T.B., J.Đ. and M.K., results validation, N.H., M.K. and T.B., writing - original draft preparation, N.H., T.B., J.Đ., M.K. and I.K., writing-review and editing, M.Z. and I.K. All authors have read and agreed to the published version of the manuscript.

Funding: This work has been supported in part by the Croatian Science Foundation under the project WINDLIPS-WIND energy integration in Low Inertia Power System (grant No. HRZZ-PAR-02-201703) and in part by H2020 project CROSSBOW (Grant 773430). This document has been produced with the financial assistance of the EU. The contents of this document are the sole responsibility of authors and can under no circumstances be regarded as reflecting the position of the EU.

Institutional Review Board Statement: Not applicable.

Informed Consent Statement: Not applicable.

Data Availability Statement: Data available on request.

Acknowledgments: This document has been produced with the financial assistance of the EU. The contents of this document are the sole responsibility of authors and can under no circumstances be regarded as reflecting the position of the EU.

Conflicts of Interest: The authors declare no conflict of interest.

\section{Abbreviations}

The following abbreviations are used in this manuscript:

$\begin{array}{ll}\text { AC } & \text { Alternating current } \\ \text { DC } & \text { Direct current } \\ \text { DG } & \text { Distributed generation } \\ \text { DSO } & \text { Distribution system operator } \\ \text { ENTSO-E } & \text { European Network of Transmission System Operators } \\ \text { EOTRP } & \text { Optimal connection study } \\ \text { EPS } & \text { Electric power system } \\ \text { emphH } & \text { System inertia constant (s) } \\ \text { HPP } & \text { Hydropower plant } \\ \text { I } & \text { Current (A) } \\ \text { LSTM } & \text { Long Short-term Memory }\end{array}$




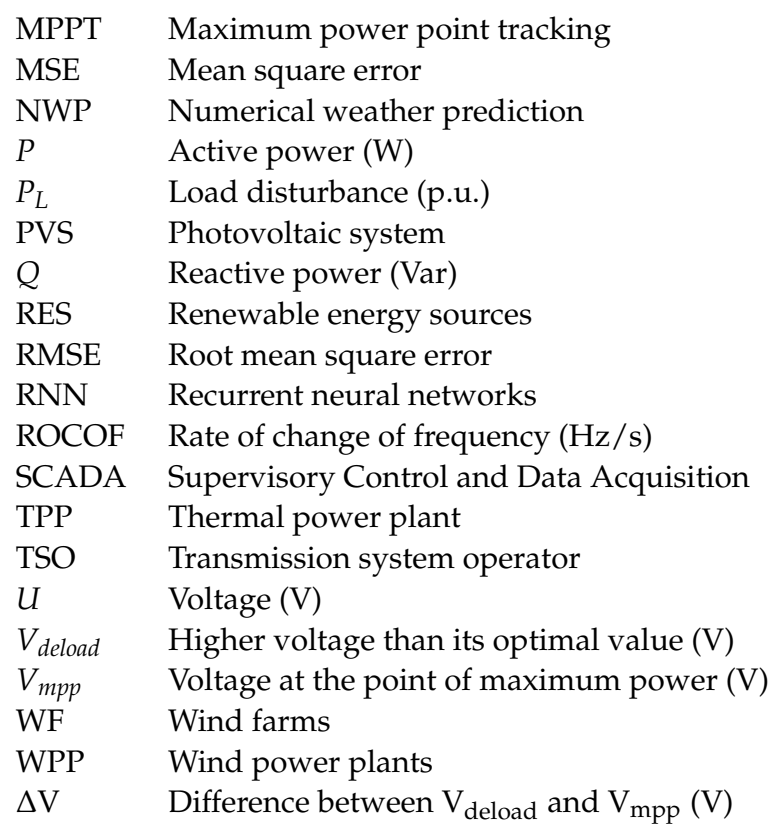

\section{References}

1. International Renewable Energy Agency. Renewable Capacity Statistics 2020; International Renewable Energy Agency: Abu Dhabi, United Arab Emirates, 2020.

2. Ackermann, T.; Prevost, T.; Vittal, V.; Roscoe, A.J.; Matevosyan, J.; Miller, N. Paving the Way: A Future Without Inertia Is Closer Than You Think. IEEE Power Energy Mag. 2017, 15, 61-69. [CrossRef]

3. Croatian Transmission System Operator. Monthly Report on Wind Power Plant Generation in Croatia; Croatian Transmission System Operator: Zagreb, Croatia, 2020.

4. Rocabert, J.; Luna, A.; Blaabjerg, F.; Rodríguez, P. Control of power converters in AC microgrids. IEEE Trans. Power Electron. 2012, 27, 4734-4749. [CrossRef]

5. Agathokleous, C.; Ehnberg, J. The Need for Additional Inertia in the European Power System until 2050 and the Contribution of Wind Power. In Proceedings of the 4th International Hybrid Power Systems Workshop, Crete, Greece, 22-23 May 2019; pp. 1-5.

6. Kundur, P.; Balu, N.J.; Lauby, M.G. Power System Stability and Control; McGraw-Hill: New York, NY, USA, 1994.

7. Kundur, P.; Paserba, J.; Ajjarapu, V.; Andersson, G.; Bose, A.; Canizares, C.; Hatziargyriou, N.; Hill, D.; Stankovic, A.; Taylor, C.; et al. Definition and classification of power system stability. IEEE Trans. Power Syst. 2004, 19, 1387-1401.

8. Zhou, Y.; Nguyen, D.D.; Kjaer, P.C.; Saylors, S. Connecting wind power plant with weak grid-Challenges and solutions. In Proceedings of the IEEE Power and Energy Society General Meeting, Vancouver, BC, Canada, 21-25 July 2013.

9. Krpan, M.; Kuzle, I. Dynamic characteristics of virtual inertial response provision by DFIG-based wind turbines. Electr. Power Syst. Res. 2020, 178, 106005. [CrossRef]

10. Rajan, R.; Fernandez, F.M. Power control strategy of photovoltaic plants for frequency regulation in a hybrid power system. Int. J. Electr. Power Energy Syst. 2019, 110, 171-183. [CrossRef]

11. Zhang, F.; Hu, Z.; Xie, X.; Zhang, J.; Song, Y. Assessment of the Effectiveness of Energy Storage Resources in the Frequency Regulation of a Single-Area Power System. IEEE Trans. Power Syst. 2017, 32, 3373-3380. [CrossRef]

12. Tielens, P.; Van Hertem, D. Grid Inertia and Frequency Control in Power Systems with High Penetration of Renewables. In Proceedings of the Young Researchers Symposium in Electrical Power Engineering, Delft, The Netherlands, 16-17 April 2012; KU Leuven: Leuven, Belgium, 2012.

13. Agathokleous, C.; Ehnberg, J. A Quantitative Study on the Requirement for Additional Inertia in the European Power System until 2050 and the Potential Role of Wind Power. Energies 2020, 13, 2309. [CrossRef]

14. Teng, F.; Aunedi, M.; Strbac, G.; Trovato, V.; Dallagi, A. Provision of ancillary services in future low-carbon UK electricity system. In Proceedings of the 2017 IEEE PES Innovative Smart Grid Technologies Conference Europe, ISGT-Europe 2017, Torino, Italy, 26-29 September 2017; Volume 2018, pp. 1-6.

15. Lenzi, V.; Ulbig, A.; Andersson, G. Impacts of forecast accuracy on grid integration of renewable energy sources. In Proceedings of the 2013 IEEE Grenoble Conference PowerTech, POWERTECH 2013, Grenoble, France, 16-20 June 2013.

16. Alhelou, H.; Hamedani-Golshan, M.-E.; Zamani, R.; Heydarian-Forushani, E.; Siano, P. Challenges and Opportunities of Load Frequency Control in Conventional, Modern and Future Smart Power Systems: A Comprehensive Review. Energies 2018, 11, 2497. [CrossRef]

17. Tambunan, H.B.; Hakam, D.F.; Prahastono, I.; Pharmatrisanti, A.; Purnomoadi, A.P.; Aisyah, S.; Wicaksono, Y.; Sandy, I.G.R. The Challenges and Opportunities of Renewable Energy Source (RES) Penetration in Indonesia: Case Study of Java-Bali Power System. Energies 2020, 13, 5903. [CrossRef] 
18. Abrahamsen, F.E.; Ruud, S.G.; Gebremedhin, A. Moving Toward a Sustainable Energy System: A Case Study of Viken County of Norway. Energies 2020, 13, 5912. [CrossRef]

19. Kling, W.L.; Ummels, B.C.; Hendriks, R.L. Transmission and system integration of wind power in the Netherlands. In Proceedings of the 2007 IEEE Power Engineering Society General Meeting, PES, Tampa, FL, USA, 24-28 June 2007.

20. Ntomalis, S.; Iliadis, P.; Atsonios, K.; Nesiadis, A.; Nikolopoulos, N.; Grammelis, P. Dynamic Modeling and Simulation of Non-Interconnected Systems under High-RES Penetration: The Madeira Island Case. Energies 2020, 13, 5786. [CrossRef]

21. Curto, D.; Favuzza, S.; Franzitta, V.; Musca, R.; Navarro Navia, M.A.; Zizzo, G. Evaluation of the optimal renewable electricity mix for Lampedusa island: The adoption of a technical and economical methodology. J. Clean. Prod. 2020, 263, 121404. [CrossRef]

22. Crainz, M.; Curto, D.; Franzitta, V.; Longo, S.; Montana, F.; Musca, R.; Sanseverino, E.R.; Telaretti, E. Flexibility Services to Minimize the Electricity Production from Fossil Fuels. A Case Study in a Mediterranean Small Island. Energies 2019, 12, 3492. [CrossRef]

23. Jung, C.; Schindler, D.; Grau, L. Achieving Germany's wind energy expansion target with an improved wind turbine siting approach. Energy Convers. Manag. 2018, 173, 383-398. [CrossRef]

24. De Simón-Martín, M.; De La Puente-Gil, Á.; Borge-Diez, D.; Ciria-Garcés, T.; González-Martínez, A. Wind energy planning for a sustainable transition to a decarbonized generation scenario based on the opportunity cost of the wind energy: Spanish Iberian Peninsula as case study. Energy Procedia 2019, 157, 1144-1163. [CrossRef]

25. Gao, Y.; Ma, S.; Wang, T.; Wang, T.; Gong, Y.; Peng, F.; Tsunekawa, A. Assessing the wind energy potential of China in considering its variability/intermittency. Energy Convers. Manag. 2020, 226, 113580. [CrossRef]

26. Cheshire, B. Offshore wind playing a lead role in the UK's green energy transformation. In Renewable Energy Focus; Elsevier Ltd.: Amsterdam, The Netherlands, 2016; Volume 17, pp. 23-24.

27. Clegg, S.; Mancarella, P. Integrated Modeling and Assessment of the Operational Impact of Power-to-Gas (P2G) on Electrical and Gas Transmission Networks. IEEE Trans. Sustain. Energy 2015, 6, 1234-1244. [CrossRef]

28. Guandalini, G.; Robinius, M.; Grube, T.; Campanari, S.; Stolten, D. Long-term power-to-gas potential from wind and solar power: A country analysis for Italy. Int. J. Hydrogen Energy 2017, 42, 13389-13406. [CrossRef]

29. Binder, H. Power Control for Wind Turbines in Weak Grids; Risø National Laboratory: Roskilde, Denmark, 1999.

30. Tande, J.O.G. Exploitation of wind-energy resources in proximity to weak electric grids. Appl. Energy 2000, 65, 395-401. [CrossRef]

31. Croatian Transmission System Operator. Network Connection. Available online: https://www.hops.hr/en/network-connection (accessed on 30 December 2020).

32. Capuder, T.; Pandžić, H.; Kuzle, I.; Škrlec, D. Specifics of integration of wind power plants into the Croatian transmission network. Appl. Energy 2013, 101, 142-150. [CrossRef]

33. Home-DIgSILENT. Available online: https://www.digsilent.de/en/ (accessed on 30 December 2020).

34. Đaković, J.; Krpan, M.; Ilak, P.; Baškarad, T.; Kuzle, I. Impact of wind capacity share, allocation of inertia and grid configuration on transient RoCoF: The case of the Croatian power system. Int. J. Electr. Power Energy Syst. 2020, 121, 106075. [CrossRef]

35. Dreidy, M.; Mokhlis, H.; Mekhilef, S. Inertia response and frequency control techniques for renewable energy sources: A review. Renew. Sustain. Energy Rev. 2017, 69, 144-155. [CrossRef]

36. Poolla, B.K.; Groß, D.; Dörfler, F. Placement and Implementation of Grid-Forming and Grid-Following Virtual Inertia and Fast Frequency Response. IEEE Trans. Power Syst. 2019, 34, 3035-3046. [CrossRef]

37. Rakhshani, E.; Rouzbehi, K.; Sánchez, A.J.; Tobar, A.C.; Pouresmaeil, E. Integration of Large Scale PV-Based Generation into Power Systems: A Survey. Energies 2019, 12, 1425. [CrossRef]

38. Cabrera-Tobar, A.; Bullich-Massagué, E.; Aragüés-Peñalba, M.; Gomis-Bellmunt, O. Review of advanced grid requirements for the integration of large scale photovoltaic power plants in the transmission system. Renew. Sustain. Energy Rev. 2016, 62, 971-987. [CrossRef]

39. Tavakkoli, M.; Adabi, J.; Zabihi, S.; Godina, R.; Pouresmaeil, E. Reserve Allocation of Photovoltaic Systems to Improve Frequency Stability in Hybrid Power Systems. Energies 2018, 11, 2583. [CrossRef]

40. Baškarad, T.; Kuzle, I.; Holjevac, N. Photovoltaic System Power Reserve Determination Using Parabolic Approximation of Frequency Response. IEEE Trans. Smart Grid 2021. under review.

41. Huang, C.-J.; Kuo, P.-H. A Short-Term Wind Speed Forecasting Model by Using Artificial Neural Networks with Stochastic Optimization for Renewable Energy Systems. Energies 2018, 11, 2777. [CrossRef]

42. Giebel, G.; Draxl, C.; Brownsword, R.; Kariniotakis, G.; Denhard, M. The State-Of-The-Art in Short-Term Prediction of Wind Power A Literature Overview; ANEMOS Project: Roskilde, Denmark, 2004; p. 36.

43. Đaković, J.; Kuzle, I. Status and classification of methods for predicting electric power production from wind power plants. In Proceedings of the 13th Symposium on Power System Management, Rovinj, Croatia, 5-7 November 2018; p. 10. 